\title{
Article \\ A Comparison of Manual Nylon Bristle Toothbrushes versus Thermoplastic Elastomer Toothbrushes in Terms of Cleaning Efficacy and the Biological Potential Role on Gingival Health
}

\author{
Andrea Ballini ${ }^{1,2, *,+} \oplus$, Michele Di Cosola ${ }^{3, \dagger}{ }^{,}$, Rajiv Saini ${ }^{4}$, Caterina Benincasa ${ }^{5}$, Elisabetta Aiello ${ }^{5}$, \\ Benedetta Marrelli ${ }^{5}$, Sugandha Rajiv Saini ${ }^{4}$, Francesco Mattia Ceruso ${ }^{6}$, Riccardo Nocini ${ }^{7}$, Skender Topi ${ }^{8}$, \\ Lucrezia Bottalico ${ }^{9}$, Francesco Pettini ${ }^{4, \ddagger}$ and Stefania Cantore ${ }^{4, *, \mp(\mathbb{D}}$
}

Citation: Ballini, A.; Di Cosola, M. Saini, R.; Benincasa, C.; Aiello, E.; Marrelli, B.; Rajiv Saini, S.; Ceruso, F.M.; Nocini, R.; Topi, S.; et al. A Comparison of Manual Nylon Bristle Toothbrushes versus Thermoplastic Elastomer Toothbrushes in Terms of Cleaning Efficacy and the Biological Potential Role on Gingival Health. Appl. Sci. 2021, 11, 7180. https:// doi.org/10.3390/app11167180

Academic Editor: Gabriele Cervino

Received: 20 June 2021

Accepted: 2 August 2021

Published: 4 August 2021

Publisher's Note: MDPI stays neutral with regard to jurisdictional claims in published maps and institutional affiliations.

Copyright: (C) 2021 by the authors Licensee MDPI, Basel, Switzerland. This article is an open access article distributed under the terms and conditions of the Creative Commons Attribution (CC BY) license (https:// creativecommons.org/licenses/by/ $4.0 /)$
School of Medicine, University of Bari "Aldo Moro", 70124 Bari, Italy

2 Department of Precision Medicine, University of Campania "Luigi Vanvitelli", 80138 Naples, Italy

3 Department of Clinical and Experimental Medicine, Università degli Studi di Foggia, 71122 Foggia, Italy; michele.dicosola@unifg.it

4 Department Interdisciplinary of Medicine, University of Bari “Aldo Moro", 70124 Bari, Italy; sorriso.benessere@gmail.com (R.S.); specialistmdc@gmail.com (S.R.S.); francesco.pettini@uniba.it (F.P.)

5 Marrelli Health-Tecnologica Research Institute, Biomedical Section, Street E. Fermi, 88900 Crotone, Italy; caterina.benincasa@leverdipraterie.com (C.B.); elisa.aiello@tecnologicasrl.com (E.A.);

benedetta.marrelli@calabrodental.it (B.M.)

6 Department of Dentistry “Fra G.B. Orsenigo-Ospedale San Pietro F.B.F.”, 00100 Rome, Italy; f.m.ceruso@gmail.com

7 Section of Ear Nose and Throat (ENT), Department of Surgical Sciences, Dentistry, Gynecology and Pediatric, University of Verona, 37126 Verona, Italy; sorrisoebenessere@libero.it

8 School of Technical Medical Sciences, “A. Xhuvani” University, 3001 Elbasan, Albania; skender.topi@uniel.edu.al

9 Interdepartmental Research Center for Pre-Latin, Latin and Oriental Rights and Culture Studies (CEDICLO), University of Bari “A. Moro", 70121 Bari, Italy; bottalico.lu@gmail.com

* Correspondence: andrea.ballini@me.com (A.B.); stefaniacantore@pec.omceo.bari.it (S.C.)

+ These authors equally served as co-first authors.

$\ddagger$ These authors equally served as co-last authors.

Featured Application: This study was designed to evaluate changes in toothbrush-dependent oral hygiene scores as well as plaque removal efficacy measured as the Oral Hygiene Index (OHI), Gingival Index (GI) and Plaque Index (PI), comparing an entirely rubber-like material called thermoplastic elastomer with a soft toothbrush (nylon bristles, standard control).

Abstract: Background: It is well-known that toothbrushing might be associated with the development of oral soft tissue lesions. There is currently a continuing increase in the demand for new safety and performing materials in daily homecare oral hygiene including soft and extra-soft toothbrush bristles that tend to be safer. The aim of this study was to compare the efficacy of plaque control and the potential effects on gingival health of two different toothbrush bristle models. Methods: In a three-month period, a total of forty subjects were evaluated for Oral Hygiene Index (OHI), Gingival Index (GI) and Plaque Index (PI) scores as well the Gingival Abrasion Assessment (GAA) between a toothbrush entirely made from a rubber-like material called thermoplastic elastomer (TPE) and a soft toothbrush (standard control with nylon bristles) in a clinical, single-blind, controlled, parallel-group trial. Results: The use of the TPE toothbrush allows a reduction in the PI, improves the OHI and modifies the GAA in the TPE group over a period of three months compared with a conventional soft bristle toothbrush applied for the same period, leading in this way evidence for a good influence of the TPE bristles on overall oral hygiene conditions. Conclusions: From the comparison between our data and the literature studies, we can state that the material and shape of the bristles of the toothbrush affect the home practice of oral hygiene. The TPE bristles reduce the presence of plaque formation and gingival bleeding, oral soft tissue injuries acquired during homecare oral hygiene.

Keywords: oral hygiene; dental devices; dental plaque; gingival recession; homecare; soft tissue injuries; toothbrushing; thermoplastic elastomer (TPE); recyclable material; sustainability 


\section{Introduction}

Personal and professional oral hygiene practices are the procedures directed at the removal of dental plaque. A toothbrush is one of the most commonly used adjuncts for maintaining oral hygiene [1]. The design of the modern conventional manual toothbrush can be attributed to Dr. Robert Hutson, a Californian periodontist, who, in the early 1950s, developed a multi-tufted, flat-trimmed, end-rounded nylon filament brush that became known as the OralB manual toothbrush [2].

That original design - a plastic handle with carefully end-rounded vertical nylon filaments - was used in various forms for many years and, with minor design modifications, remains the mainstay of plaque removal worldwide [2-7]. It is well-known that most people use a simple horizontal toothbrushing action and brush their teeth for a duration markedly shorter than the optimal time [7]. Good standards of oral hygiene have frequently been associated with soft tissue lesions, which may be a consequence of traumatic toothbrushing [3]. One common soft tissue lesion caused by toothbrushing is gingival abrasion. Several randomized controlled trials (RCTs) have reported the development of this condition following manual toothbrushing [3].

Manufacturers of toothbrushes aim for innovations in the brush head design that will help to compensate for a non-ideal toothbrushing technique and time [8-10]. The more basic designs include toothbrushes with standard (straight) bristles and more advanced models include angled bristles specially aimed at helping the removal of plaque from teeth and along the gum line [10-13]. By the turn of the 21st century, nylon was widely used for the bristles and the handles were usually molded from thermoplastic materials.

Advanced toothbrushes, i.e., manufactured, bristles included, from a rubber-like material called thermoplastic elastomer (TPE), have the potential to remove greater amounts of plaque, especially from the gum lines and approximal surfaces, than conventional toothbrushes incorporating straight bristles [8]. On the other hand, there have been conflicting results as to which design is more capable of effective plaque control maintaining at the same time gingival health $[5-7,11]$. In addition, recycling traditional toothbrushes is very difficult because each part is made using a different kind of plastic: the handle, the bristles and the rubber grips. This is a huge issue for recycling facilities that need to separate each plastic type. The TPE combines the properties of rubber (soft and pliable) with the benefits of thermoplastics, showing a higher durability in comparison with traditional nylon bristles. The result is a flexible and recyclable material [12]. In fact, TPE materials can be processed and recycled like thermoplastics but they have similar properties and performance to thermoset rubber materials [12]. However, at the moment, it is not clear how effective a TPE is in removing bacterial plaque as well the safety for oral soft tissues as no clinical trial has been published on this type of toothbrush bristle to the knowledge of the authors. Therefore, the aim of this study was to compare the efficacy of plaque control and the potential effects on gingival health of two different toothbrush bristle models.

\section{Materials and Methods}

\subsection{Participants}

All subjects who responded to the recruitment advertisements were screened by the investigators to determine eligibility. The study was carried out according to the Helsinki declaration and informed written consent was obtained from all patients included in the study. Eligible participants were 40 healthy subjects ( 20 males and 20 females; $36 \pm 4$ years old) and were enrolled in this study based on the following inclusion criteria: (1) good general and oral health, (2) minimum of 24 natural teeth, (3) subjects reported brushing at least twice daily, (4) using no other means of oral hygiene except toothbrushing.

Subjects were excluded from the study based on the following exclusion criteria: (1) caries, periodontal diseases or oral lesions; (2) smoking habits; (3) fixed orthodontic appliances; (4) removable dentures or an extended fixed prosthesis; (5) a present history of medications that are likely to affect oral health; (6) therapy with antibiotics within 2 months before the enrollment; (7) failure to obtain the informed consent. 


\subsection{Experimental Design}

This research was conducted in collaboration with the Elbasan University "A. Xhuvani" (School of Technical Medical Sciences), Elbasan, Albania, a dental community cabinet (Sorriso \& Benessere-Ricerca e Clinica SRL, Bari, Italy) and the University of Bari Aldo Moro, Bari, Italy for a three-month period. Participants who met the inclusion criteria were assigned into two different groups.

The subjects (20 for each group) were then classified into two treatment regimens (toothbrushes): Group I $(n=20)$ : Test, Boie toothbrush, USA (made from a rubber-like material called thermoplastic elastomer) and Group II $(n=20)$ : Control (standard toothbrush, soft bristles).

Participants were asked to brush their teeth for at least two minutes twice a day for ten weeks. To avoid the effect of new variables, a basic non-medicated fluoride-free toothpaste (galenic formulation) was, on purpose, prepared for this study and provided to all participants.

During the study period, the subjects were asked not to use mouthwash. Patients were also asked to practice the home brushing technique known as Bass's Modified Technique: it was properly explained to patients during the first recruitment stage. Bass's Modified Technique is, in brief, a brushing technique involving the slow rotation of the toothbrush towards the coronal direction so to effectively remove the bacteria deeply located within in the dental plaque; moreover, this technique involves also slow movements of pressure and vibration within the gingival sulcus. This technique is widely recommended to all patients and it can be used also in the presence of deep periodontal pockets. The Institutional Ethics Committee of the Faculty of Technical Medical Sciences of Elbasan "Aleksandër Xhuvani" approved the application to conduct the clinical trial in the faculty, Protocol Identification: INTL_ALITCOOP/DentPath/2020_SLK.

\subsection{Clinical Parameters}

The clinical parameters (scores including the Oral Hygiene Index (OHI), Gingival Index (GI) and Plaque Index (PI)) were taken from all participants by the same blinded trained examiner at the baseline and at the end of the study [14-18].

\subsubsection{Plaque Index: (Silness and Loe)}

Plaque was assessed on the distal, buccal, mesial, lingual or palatal area of each tooth. These areas were assigned a score between 0 and 3 . The plaque score for a tooth was obtained by totaling the score for each area and dividing by 4 . The plaque score per person was obtained by adding the plaque score for each tooth and dividing by the total number of teeth examined $[15,16]$.

\subsubsection{Simplified Oral Hygiene Index (Greene and Vermillion)}

The Simplified Oral Hygiene Index (OHI) has two components, the Debris Index and the Calculus Index [17]. Each of these indices, in turn, is based on numerical determinations representing the amount of debris or calculus found on the preselected tooth surface.

The six surfaces examined for the $\mathrm{OHI}$ are selected from four posterior (first molar or, in the case of missing teeth, it is possible to consider as a substitution the second or third molar) and two anterior teeth.

The six surfaces examined for the OHI-S are selected from four posterior and two anterior teeth.

The buccal surfaces of the selected upper molars and lingual surfaces of the selected lower molars are inspected. For the anterior teeth, the buccal surfaces of the upper right and the lower left central incisors are scored. In the absence of either of these anterior teeth, the central incisor ( 21 or 41 respectively) on the opposite side of the midline could be substituted [17]. 


\subsubsection{Gingival Abrasion Assessment}

The participants were asked not to perform any oral hygiene $48 \mathrm{~h}$ from the end of the study, thus allowing the accumulation of plaque. In the professional hygiene session, the gums were dried with compressed air and a revealing solution was applied for a better visualization of the areas where the surface of the oral epithelium had been abraded. The gingival tissues were divided into three areas: marginal (free cervical gingiva), interdental (free papillary gingiva) and mid-gingival (attached gingiva). Lesions were assessed as small ( $\leq 2 \mathrm{~mm})$, medium $(3-5 \mathrm{~mm})$ and large $(>5 \mathrm{~mm})$ using a periodontal probe.

To better classify patients according to their gingival lesions, we modified the Gingival Abrasion Assessment (GAA), reporting the value "Healthy" in the case of small to moderate lesions (from $\leq 2 \mathrm{~mm}$ to $\leq 4 \mathrm{~mm}$ ) and "Not Healthy" in the case of moderate to large lesions (from $>4 \mathrm{~mm}$ to $>5 \mathrm{~mm}$. We only investigated the anterior gingival area of both maxillary bones. The baseline of the patients was considered to be the starting value compared with the value observed on the second examination. Patients were asked to brush their teeth by themselves as usually performed in their daily oral hygiene [18].

\subsubsection{Statistical Analysis}

The data underwent a statistical analysis. As previously reported in similar studies, oral indices were calculated as a percentage of the relative score ranges. For each group, descriptive statistics were calculated. The quantitative data were reported as a mean and a standard deviation (SD) and the comparisons between groups were valued by the twosample Student's $t$-test and the degree of freedom (DF) was set to $=38$. A $p$-value $\leq 0.05$ was considered statistically significant.

The statistical analyses for pre-post difference scores were performed by using GraphPad Prism 9.2 software. Moreover, there were no baseline differences among the two groups with respect to age and clinical parameters.

\section{Results}

The results are reported in Tables 1 and 2 and the following four Figures, showing the variables that were considered during our study in order to evaluate the effectiveness of the Boie toothbrush compared with a conventional soft toothbrush in the treated subjects and in the group control during the three-month experimental period.

Table 1. Statistical comparison for each clinical measure in the groups at two different time points (T0-T1).

\begin{tabular}{|c|c|c|c|c|c|c|c|c|}
\hline Clinical Indices and Groups & Baseline (T0) & & & & e Months & & & \\
\hline Plaque Index & $p$-value & $t$-test & Mean & SD & $p$-value & $t$-test & Mean & SD \\
\hline Test Group & 0.2189 & 1.250 & 1.015 & 0.6915 & 0.1226 & 1.579 & 0.79 & 0.583 \\
\hline Control Group & & & 1.32 & 0.8439 & & & 1.155 & 0.8538 \\
\hline Debris Index & $p$-value & $t$-test & Mean & SD & $p$-value & $t$-test & Mean & SD \\
\hline Test Group & 0.5659 & 0.5792 & 0.88 & 0.6614 & 0.4059 & 0.8406 & 0.73 & 0.5391 \\
\hline Control Group & & & 1.02 & 0.8551 & & & 0.915 & 0.8235 \\
\hline Calculus Index & $p$-value & $t$-test & Mean & SD & $p$-value & $t$-test & Mean & SD \\
\hline Test Group & 0.4461 & 0.7700 & 0.865 & 0.6604 & 0.2555 & 1.155 & 0.68 & 0.5146 \\
\hline Control Group & & & 1.05 & 0.8476 & & & 0.925 & 0.7973 \\
\hline Oral Hygiene Index & $p$-value & $t$-test & Mean & SD & $p$-value & $t$-test & Mean & $\mathrm{SD}$ \\
\hline Test Group & 0.4971 & 0.6856 & 1.745 & 1.306 & 0.307 & 1.036 & 1.41 & 0.9689 \\
\hline Control Group & & & 2.07 & 1.67 & & & 1.84 & 1.584 \\
\hline
\end{tabular}

As reported in Table 1, no significant statistical difference was found between the groups. On the other hand, the current result as this clinical pilot study, presented a highly similar comparable methodology among groups (the same basic non-medicated fluoride-free toothpaste, no mouthwash use and the same home brushing technique); the only variable was the bristles used. Moreover, the study duration was not so long to justify any specific change in the clinical indices considering the low degree of impact related to 
the bristles used. Nevertheless, this study clearly suggests a tendency related to the ability to ensure the maintenance of the clinical indices for the TPE bristles in comparison with the standard soft bristles.

Figure 1 assesses and reports the data regarding the plaque index in both groups at the initial time and at the end of treatment. To facilitate the understanding of the graph, the mean values of the plaque index were used for the two different groups. For the test group (20 subjects), the percentage decreased to $21.78 \%$. In an absolute value, the decrease was 0.22 . For the control group ( 20 subjects), however, the percentage of decrease was $13 \%$ from the initial time to the final time. In an absolute value, the decrease was 0.17 . From these data it is clear that between the two groups there was a percentage difference equal to $8.91 \%$.

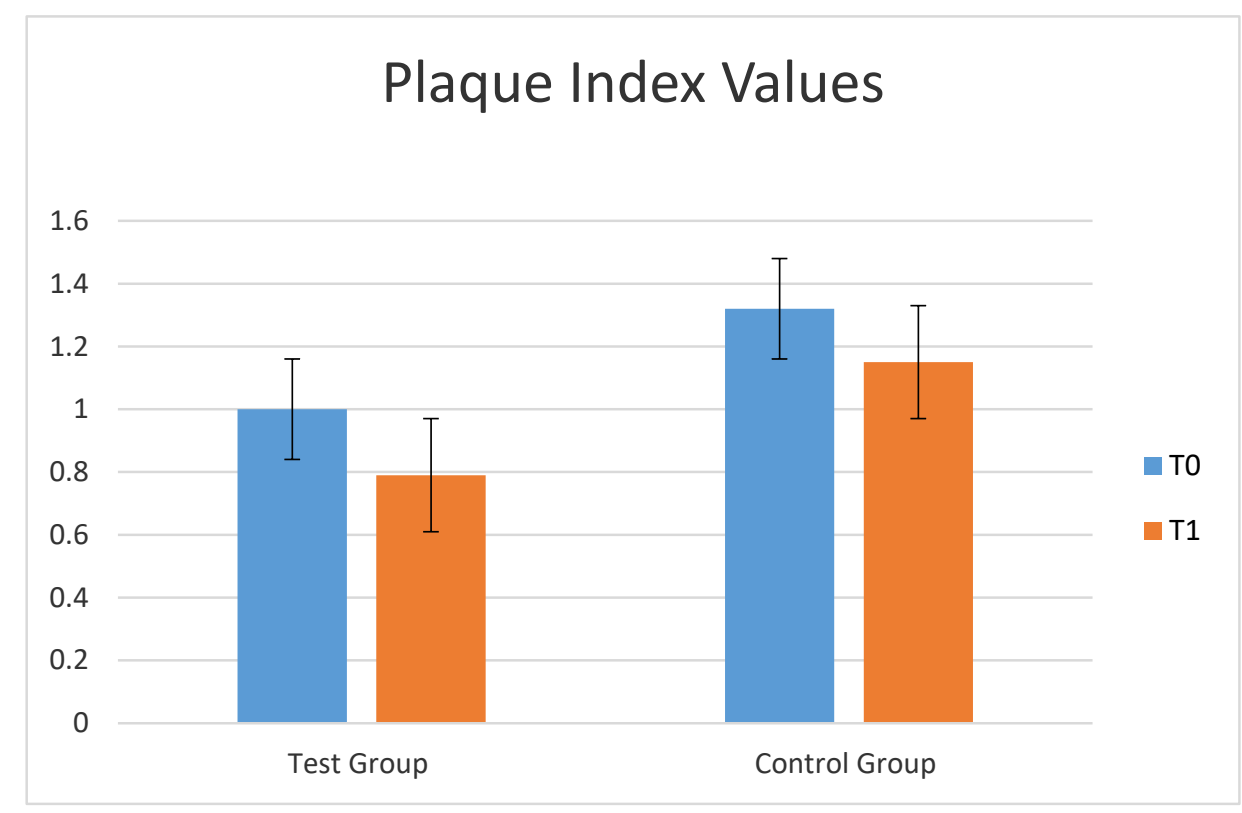

Figure 1. Plaque Index (score) evaluated in both test and control groups at two different time points (T0-T1).

Figure 2 shows the data of the Oral Hygiene Index of the test group (20 subjects). The data specifically refer to the average of the values for each specific parameter evaluated. Specifically, the data collected concern the Debris Index and Calculus Index whose sum gives us the $\mathrm{OHI}$ values. The percentage decrease in the Debris Index test group was equal to $17 \%$. In an absolute value, the decrease was equal to 0.15 . For the Calculus Index, the percentage decrease was equal to $20.93 \%$. In an absolute value, the decrease between the two times was 0.18 . The OHI, which collects both values, showed a percentage decrease equal to $18.96 \%$. In an absolute value, the decrease was 0.33 .

The same parameters were evaluated for the control group (20 subjects), as shown in Figure 3. The Figure shows that for the Debris Index parameter, the percentage of decrease was equal to $10.78 \%$. In an absolute value, the decrease was 0.11 . For the other parameter taken into consideration, namely, the Calculus Index, the percentage of decrease reported between the two intervention times was $12.38 \%$. In an absolute value, the decrease was equal to 0.13 . For the $\mathrm{OHI}$, the percentage decrease was equal to $11.59 \%$. In an absolute value, the decrease was 0.24 . In the end, it could be stated that the percentage difference between the two groups at the two times for the Debris Index parameter was $6.26 \%$, for the Calculus Index it was $8.55 \%$ and for the $\mathrm{OHI}$ it was $7.37 \%$. 


\section{Oral hygiene Index Test Group}

2.5

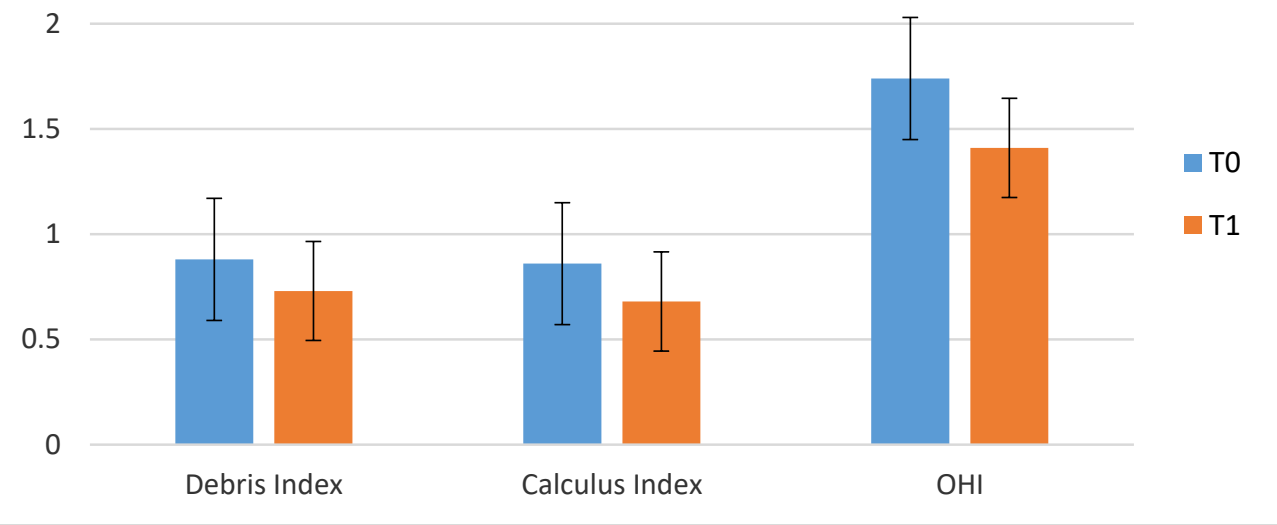

Figure 2. Oral Hygiene Index (score) reported for the test group patients at different times (T0-T1).

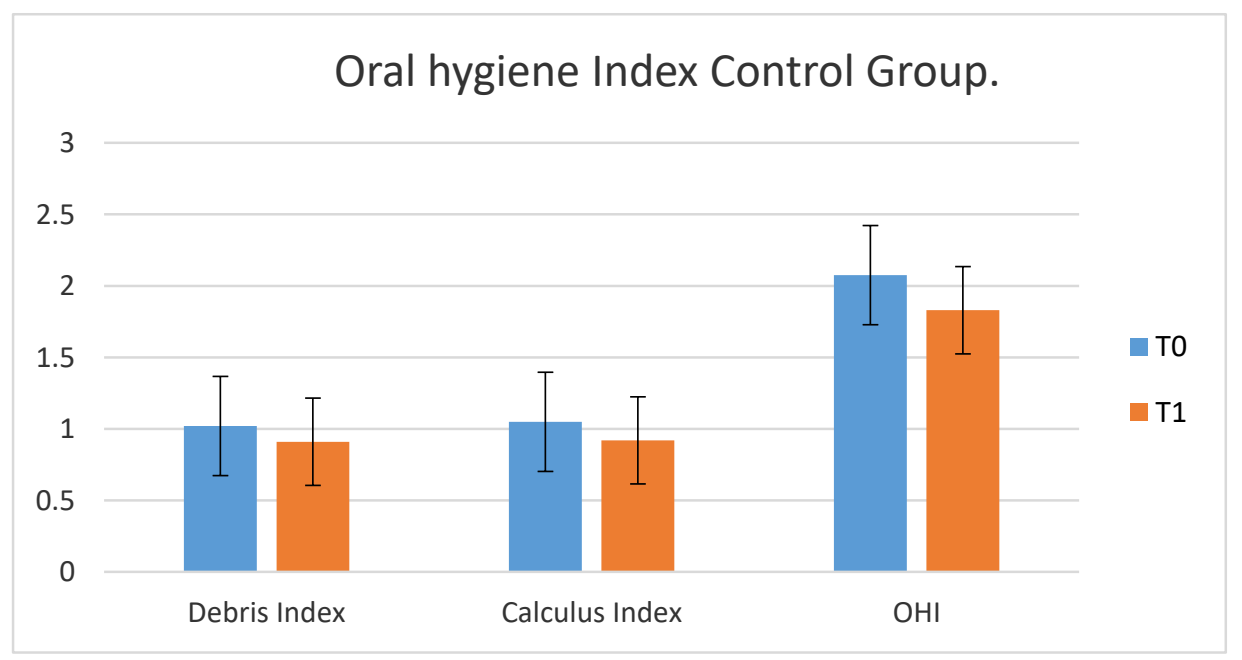

Figure 3. Oral Hygiene Index (score) reported in the control group at different times (T0-T1).

Table 2 shows the data relating to the evaluation of the gingival abrasion areas (Figures 4 and 5) detected after a time of $48 \mathrm{~h}$ without daily oral hygiene. Figure 4 specifically shows the areas of gingival abrasion that could be evaluated, i.e., mid-gingival, interdental and marginal. Figure 5, on the other hand, shows the oral hygiene in two subjects treated $48 \mathrm{~h}$ after the end of the experiment to evaluate the GAA.

Data collected for the test group (a total of 20 subjects) showed that $75 \%$ of subjects maintained a stable gingival health $(\mathrm{H}-\mathrm{H})$ after using a revealing solution that highlighted the abrasive surfaces of the oral epithelium. 


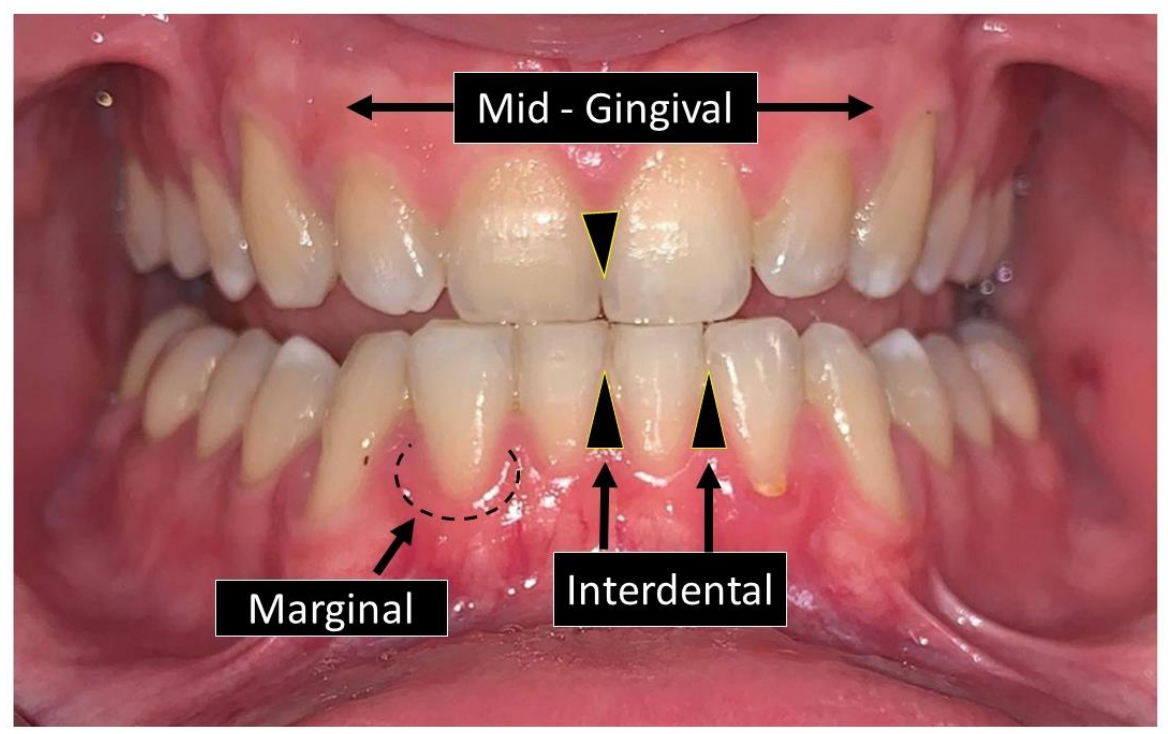

Figure 4. This figure schematizes the areas used for evaluating gingival abrasions: mid-gingival, interdental and marginal.

Table 2. Gingival Abrasion Assessment $\left({ }^{1}:\right.$ end of study; ${ }^{2}: 48 \mathrm{~h}$ after finishing the study and without brushing teeth; ${ }^{3}$ : interdental; ${ }^{4}$ : mid-gingival; ${ }^{5}$ : marginal; ${ }^{6}$ : healthy (from $\leq 2 \mathrm{~mm}$ to $\leq 4 \mathrm{~mm}$ ); ${ }^{7}$ : not healthy (from $>4 \mathrm{~mm}$ to $>5 \mathrm{~mm}$ ).

\begin{tabular}{|c|c|c|c|c|c|c|c|c|c|c|c|c|}
\hline \multirow[b]{3}{*}{ N. } & \multicolumn{6}{|c|}{ Test Group } & \multicolumn{6}{|c|}{ Control Group } \\
\hline & \multicolumn{3}{|c|}{ T0 ${ }^{1}$} & \multicolumn{3}{|c|}{$T x^{2}$} & \multicolumn{3}{|c|}{ T0 } & \multicolumn{3}{|c|}{ Tx } \\
\hline & $I^{3}$ & $\mathrm{MG}^{4}$ & $M^{5}$ & I & MG & $\mathbf{M}$ & I & MG & $\mathbf{M}$ & $\mathbf{I}$ & MG & $\mathbf{M}$ \\
\hline 1. & $\mathrm{H}^{6}$ & $\mathrm{H}$ & $\mathrm{H}$ & $\mathrm{H}$ & $\mathrm{H}$ & $\mathrm{H}$ & $\mathrm{H}$ & $\mathrm{H}$ & $\mathrm{H}$ & $\mathrm{NH}^{7}$ & $\mathrm{NH}$ & $\mathrm{NH}$ \\
\hline 2. & $\mathrm{H}$ & $\mathrm{H}$ & $\mathrm{H}$ & NH & $\mathrm{NH}$ & $\mathrm{NH}$ & $\mathrm{H}$ & $\mathrm{H}$ & $\mathrm{H}$ & $\mathrm{H}$ & $\mathrm{H}$ & $\mathrm{H}$ \\
\hline 3. & $\mathrm{H}$ & $\mathrm{H}$ & $\mathrm{H}$ & $\mathrm{H}$ & $\mathrm{H}$ & $\mathrm{H}$ & $\mathrm{H}$ & $\mathrm{H}$ & $\mathrm{H}$ & $\mathrm{NH}$ & NH & $\mathrm{NH}$ \\
\hline 4. & $\mathrm{H}$ & $\mathrm{H}$ & $\mathrm{H}$ & $\mathrm{H}$ & $\mathrm{H}$ & $\mathrm{H}$ & $\mathrm{H}$ & $\mathrm{H}$ & $\mathrm{H}$ & $\mathrm{H}$ & $\mathrm{H}$ & $\mathrm{H}$ \\
\hline 5. & $\mathrm{H}$ & $\mathrm{H}$ & $\mathrm{H}$ & $\mathrm{H}$ & $\mathrm{H}$ & $\mathrm{H}$ & $\mathrm{H}$ & $\mathrm{H}$ & $\mathrm{H}$ & $\mathrm{H}$ & $\mathrm{H}$ & $\mathrm{H}$ \\
\hline 6. & $\mathrm{H}$ & $\mathrm{H}$ & $\mathrm{H}$ & $\mathrm{H}$ & $\mathrm{H}$ & $\mathrm{H}$ & $\mathrm{H}$ & $\mathrm{H}$ & $\mathrm{H}$ & $\mathrm{H}$ & $\mathrm{H}$ & $\mathrm{H}$ \\
\hline 7. & $\mathrm{H}$ & $\mathrm{H}$ & $\mathrm{H}$ & $\mathrm{H}$ & $\mathrm{H}$ & $\mathrm{H}$ & $\mathrm{H}$ & $\mathrm{H}$ & $\mathrm{H}$ & $\mathrm{H}$ & $\mathrm{H}$ & $\mathrm{H}$ \\
\hline 8. & $\mathrm{H}$ & $\mathrm{H}$ & $\mathrm{H}$ & $\mathrm{H}$ & $\mathrm{H}$ & $\mathrm{H}$ & $\mathrm{H}$ & $\mathrm{H}$ & $\mathrm{H}$ & $\mathrm{H}$ & $\mathrm{H}$ & $\mathrm{H}$ \\
\hline 9. & NH & NH & $\mathrm{NH}$ & NH & NH & NH & $\mathrm{H}$ & $\mathrm{H}$ & $\mathrm{H}$ & $\mathrm{H}$ & $\mathrm{H}$ & $\mathrm{H}$ \\
\hline 10. & $\mathrm{H}$ & $\mathrm{H}$ & $\mathrm{H}$ & $\mathrm{H}$ & $\mathrm{H}$ & $\mathrm{H}$ & $\mathrm{H}$ & $\mathrm{H}$ & $\mathrm{H}$ & $\mathrm{H}$ & $\mathrm{H}$ & $\mathrm{H}$ \\
\hline 11. & $\mathrm{H}$ & $\mathrm{H}$ & $\mathrm{H}$ & $\mathrm{H}$ & $\mathrm{H}$ & $\mathrm{H}$ & $\mathrm{H}$ & $\mathrm{H}$ & $\mathrm{H}$ & $\mathrm{H}$ & $\mathrm{H}$ & $\mathrm{H}$ \\
\hline 12. & $\mathrm{H}$ & $\mathrm{H}$ & $\mathrm{H}$ & $\mathrm{H}$ & $\mathrm{H}$ & $\mathrm{H}$ & $\mathrm{NH}$ & $\mathrm{NH}$ & $\mathrm{NH}$ & NH & NH & $\mathrm{NH}$ \\
\hline 13. & $\mathrm{H}$ & $\mathrm{H}$ & $\mathrm{H}$ & NH & NH & NH & $\mathrm{H}$ & $\mathrm{H}$ & $\mathrm{H}$ & $\mathrm{H}$ & $\mathrm{H}$ & $\mathrm{H}$ \\
\hline 14. & $\mathrm{NH}$ & NH & $\mathrm{NH}$ & $\mathrm{NH}$ & $\mathrm{NH}$ & $\mathrm{NH}$ & $\mathrm{H}$ & $\mathrm{H}$ & $\mathrm{H}$ & $\mathrm{H}$ & $\mathrm{H}$ & $\mathrm{H}$ \\
\hline 15. & $\mathrm{H}$ & $\mathrm{H}$ & $\mathrm{H}$ & $\mathrm{H}$ & $\mathrm{H}$ & $\mathrm{H}$ & $\mathrm{NH}$ & NH & $\mathrm{NH}$ & NH & NH & $\mathrm{NH}$ \\
\hline 16. & $\mathrm{H}$ & $\mathrm{H}$ & $\mathrm{H}$ & $\mathrm{H}$ & $\mathrm{H}$ & $\mathrm{H}$ & $\mathrm{NH}$ & NH & $\mathrm{NH}$ & $\mathrm{NH}$ & $\mathrm{NH}$ & $\mathrm{NH}$ \\
\hline 17. & $\mathrm{H}$ & $\mathrm{H}$ & $\mathrm{H}$ & $\mathrm{H}$ & $\mathrm{H}$ & $\mathrm{H}$ & $\mathrm{NH}$ & $\mathrm{NH}$ & $\mathrm{NH}$ & $\mathrm{NH}$ & NH & $\mathrm{NH}$ \\
\hline 18. & $\mathrm{NH}$ & NH & $\mathrm{NH}$ & NH & $\mathrm{NH}$ & NH & $\mathrm{H}$ & $\mathrm{H}$ & $\mathrm{H}$ & $\mathrm{H}$ & $\mathrm{H}$ & $\mathrm{H}$ \\
\hline 19. & $\mathrm{H}$ & $\mathrm{H}$ & $\mathrm{H}$ & $\mathrm{H}$ & $\mathrm{H}$ & $\mathrm{H}$ & $\mathrm{H}$ & $\mathrm{H}$ & $\mathrm{H}$ & $\mathrm{H}$ & $\mathrm{H}$ & $\mathrm{H}$ \\
\hline 20. & $\mathrm{H}$ & $\mathrm{H}$ & $\mathrm{H}$ & $\mathrm{H}$ & $\mathrm{H}$ & $\mathrm{H}$ & $\mathrm{H}$ & $\mathrm{H}$ & $\mathrm{H}$ & $\mathrm{H}$ & $\mathrm{H}$ & $\mathrm{H}$ \\
\hline
\end{tabular}

In total, $15 \%$ of the test group ( 3 treated subjects) maintained their clinical condition of non-health (NH-NH) stable; finally, $10 \%$ of the patients in the test group suffered a worsening of gingival health (from parameter $\mathrm{H}$ to $\mathrm{NH}$ ), probably due to delayed brushing after $48 \mathrm{~h}$.

Table 2 also reports the data of the control group (20 subjects) where we observed $70 \%$ of stable patients $(\mathrm{HH})$ corresponding with 14 subjects who used a traditional toothbrush; $20 \%$ were also stable $(\mathrm{NH}-\mathrm{NH})$ and $10 \%$ of subjects had a worsening of their clinical condition $(\mathrm{H}-\mathrm{NH})$. These data clearly demonstrated that the product under test with the thermoplastic bristles (Boie toothbrush) compared with the standard soft bristle toothbrush had an almost similar gingival abrasion result: in fact, a 5\% percentage difference was observed between the test group and the control group for the $\mathrm{HH}$ parameter, an equal 
$5 \%$ for the NH-NH parameter and no percentage difference for H-NH. However, there is a minor advantage of the test product over the control group with better oral hygiene results starting from a similar brushing technique and a fairly similar distribution of patients within the two investigated groups: this may indicate that elastomeric toothbrushes have been compared with other devices.
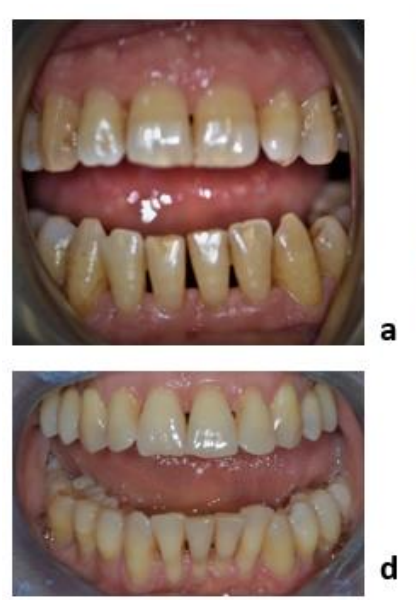
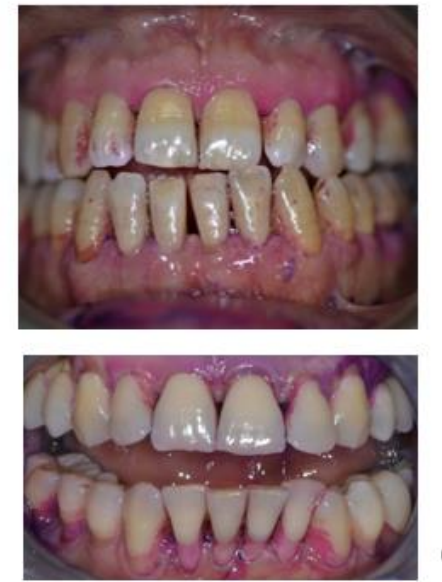
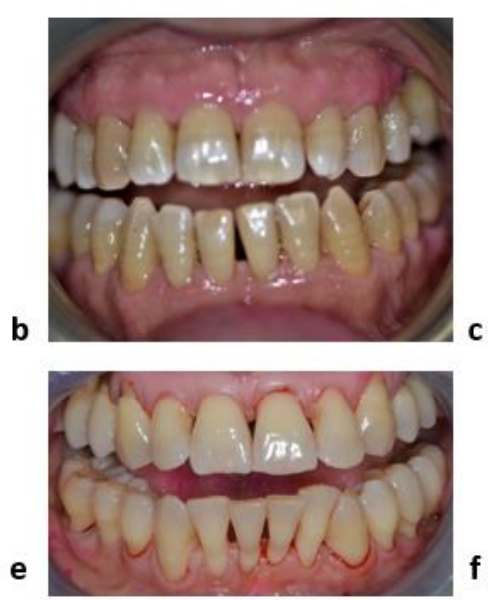

Figure 5. Oral hygiene in two different subjects $48 \mathrm{~h}$ after the end of the experimental protocol: we evaluated the overall Gingival Abrasion Assessment. (a,d) Patient before oral hygiene; (b,e) patient during treatment: the gums are dried with compressed air and a revealing solution applied for a better visualization of the areas in question; $(\mathbf{c}, \mathbf{f})$ patient after oral hygiene.

\section{Discussion}

Oral homecare health is a major concern for dental professionals [14]. Most periodontal diseases have a bacterial origin, which by producing the so-called "biofilm" lead to an increase in the accumulation of dental plaque [14-18]. To date, dental professionals recommend brushing teeth twice a day for two minutes as good oral hygiene practiced regularly can help maintain functional dentition throughout life [19]. There is, however, a wide variety of brushing methods based on position and movement and also on the type of brush used. There is no defined "ideal" technique either for the general population or for people of different ages or with particular dental conditions according to evidence-based dentistry [20-26].

Furthermore, the effectiveness of the toothbrush for removing plaque is based on several parameters including the use of a toothbrush that adapts to the mouth allowing it to reach all areas and the characteristics of the toothbrush as well as proper education in oral hygiene with instructions on movement, duration and frequency of brushing [10]. According to the data reported in the literature, both the shape and material of the bristles of a toothbrush induce changes in the plaque index. According to Yankell, a bi-level toothbrush with feathered bristles on the outer row significantly increases the ability of the bristles to reach the innermost gum areas with a percentage of $35.7 \%$ and the cleaning effectiveness of $54.5 \%$ compared with an identical bi-level brush with rounded bristle ends [5].

This pilot study was designed to evaluate changes in toothbrush-dependent oral hygiene scores as well as plaque removal efficacy measured as the OHI, GI and PI in addition to soft tissue safety, according to a GAA assessment. The rationale for this study was dictated by the increasing popularity of a new toothbrush with TPE bristles that has recently been proposed with the benefits of the thermoplastic being a flexible and recyclable material showing a higher durability with respect to traditional nylon bristles. At the baseline, the plaque scores were almost similar in all the groups during each test phase.

The percentages and statistical differences found in our study were confirmed by the data reported in the literature. In a 2011 study, the effectiveness of manual toothbrushes 
of the same type but with a different stiffness of the bristles on the removal of plaque, the development of gingivitis and tissue trauma was evaluated. The study was conducted on 40 patients, randomly divided into different groups based on the stiffness of the bristles: hard, medium or soft. After eight weeks, the subjects who had used the hard bristle toothbrush showed a much lower plaque index score than the other two groups but at the same time showed an increase in the index of papillary bleeding and many more gum lesions. On the other hand, the subjects who used medium and soft bristle toothbrushes had fewer lesions but a higher plaque index. These data allow us to state that manual toothbrushes with hard bristles can remove plaque better but can also cause more trauma to soft tissues than brushes with softer bristles [27]. In a 2020 study, the efficiency of toothbrushes on the market on proximal cleaning and plaque elimination was studied. A data analysis allowed us to indicate that the stiffer and longer bristled toothbrushes were toothbrushes that allowed the removal of plaque from the interproximal surfaces in a better and faster way [28].

In our study, the percentages were in favor of the TPE toothbrush where there was a decrease in the plaque indices from the initial time to the final time in the test group subjects compared with those who, in the same period, used a normal soft bristle toothbrush. The plaque index in the test group decreased with a percentage of $21.78 \%$ whereas in the control group it decreased with a percentage of $12.87 \%$. The change also occurred for the $\mathrm{OHI}$ and GAA. The percentage decrease in the Debris Index test group was equal to $17.04 \%$. The Debris Index parameter in the control group instead presented that the percentage of decrease was equal to $10.78 \%$. For the OHI, the percentage decrease was equal to $11.59 \%$ in the control group; in the test group, it was a reduction of $18.96 \%$. The data revealed that in the test group the use of the Boie toothbrush maintained quite good oral hygiene and improved oral health over time, even after the absence of any home oral hygiene for $48 \mathrm{~h}$; this assessment could be obtained thanks to the observation of the $75 \%$ (Healthy-Healthy) patients allocated in the test group compared with the $70 \%$ (Healthy-Healthy) patients in the control group. This percentage referred to a condition of clinical stability of those subjects who had an optimal gingival condition at the baseline and who maintained such a condition even after $48 \mathrm{~h}$ of ceasing any home oral hygiene. On the other hand, the other parameters showed data reporting substantial clinical differences. Thus, the data related to the gingival abrasion remained almost unchanged within the same group and among the two groups compared here. The results of this study showed that the shape and material of the bristles of a toothbrush had on average a good influence on clinical oral hygiene conditions (Figure 5).

Habitual toothbrushing was considered to be an additional active control because it represented the toothbrushing procedure that was commonly used by the participants. However, the efficacy and relative effectiveness of various types and materials of toothbrushes should be confirmed through long-term studies with a larger sample size, with a further assessment of the efficacy on plaque removal and soft tissue injuries along with a long-term follow-up. The adverse effects on hard and soft tissues of manual toothbrush usage over time is more often described as a secondary outcome than a primary outcome. Consequently, additional studies also measuring clinical outcomes should assess toothbrush safety over time as a primary outcome parameter [3,29].

\section{Conclusions}

In conclusion, from the comparison between our data and the studies in the literature, we can state that the material and shape of the bristles of a toothbrush affects the home practice of oral hygiene. The daily use of the Boie thermoplastic elastomer toothbrush allowed a reduction in the PI, an improvement in the $\mathrm{OHI}$ and the modification of the GAA in a test group over a period of three months compared with a conventional soft bristle toothbrush applied for the same period. The tested material for the thermoplastic elastomer bristles, in contrast to nylon bristles, reduced the presence of plaque formation and decreased gingival bleeding during homecare oral hygiene. 
Author Contributions: Substantial contributions to the conception or design of the work: A.B., S.C. and R.S.; acquisition, analysis and interpretation of data for the work: all authors; drafting the work and revising it critically for important intellectual content: A.B., S.C., M.D.C. and F.P.; final approval of the version to be published: A.B., F.P. and S.C.; agreement to be accountable for all aspects of the work in ensuring that questions related to the accuracy or integrity of any part of the work are appropriately investigated and resolved: all authors; patient investigation, A.B. and S.C.; validation and bibliographic research, F.P. and L.B. All authors have read and agreed to the published version of the manuscript.

Funding: This research received no external funding.

Institutional Review Board Statement: The study was conducted according to the guidelines of the Declaration of Helsinki. The Institutional Ethics Committee of the Faculty of Technical Medical Sciences of Elbasan "Aleksandër Xhuvani" approved the application to conduct the clinical trial in the faculty. Protocol Identification: INTL_ALITCOOP/DentPath/2020_SLK.

Informed Consent Statement: Informed consent was obtained from all subjects involved in the study. Written informed consent was obtained from the patient(s) to publish this paper.

Data Availability Statement: Data are contained within the article.

Conflicts of Interest: The authors declare no conflict of interest.

\section{Abbreviations}

OHI: Oral Hygiene Index; GI: Gingival Index; PI: Plaque Index; TPE: thermoplastic elastomer; GAA: Gingival Abrasion Assessment; H: healthy; NH: non-healthy; RCTs: randomized controlled trials.

\section{References}

1. Naik, S.P.; Punathil, S.; Shetty, P.; Jayanti, I.; Jalaluddin, M.; Avijeeta, A. Effectiveness of Different Bristle Designs of Toothbrushes and Periodontal Status among Fixed Orthodontic Patients: A Double-blind Crossover Design. J. Contemp. Dent. Pract. 2018, 19, 150-155. [CrossRef]

2. Cugini, M.; Warren, P.R. The Oral-B CrossAction manual toothbrush: A 5-year literature review. J. Can. Dent. Assoc. 2006, 72, 323. [PubMed]

3. Ranzan, N.; Muniz, F.W.M.G.; Rösing, C.K. Are bristle stiffness and bristle end-shape related to adverse effects on soft tissues during toothbrushing? A systematic review. Int. Dent. J. 2019, 69, 171-182. [CrossRef] [PubMed]

4. Petersen, P.E.; Ogawa, H. The global burden of periodontal disease: Towards integration with chronic disease prevention and control. Periodontology 2000 2012, 60, 15-39. [CrossRef]

5. Yankell, S.L.; Shi, X.; Emling, R.C.; Bucker, R.; Loudin, S. Laboratory evaluation of two bi-level toothbrush products for subgingival access and gingival margin cleaning. J. Clin. Dent. 2000, 11, 20-23. [PubMed]

6. Inchingolo, A.D.; Di Cosola, M.; Inchingolo, A.M.; Greco Lucchina, A.; Malcangi, G.; Pettini, F.; Scarano, A.; Bordea, I.R.; Hazballa, D.; Lorusso, F.; et al. Correlation between occlusal trauma and oral microbiota: A microbiological investigation. J. Biol. Regul. Homeost. Agents 2021, 35, 295-302. [CrossRef]

7. Dipalma, G.; Inchingolo, A.D.; Inchingolo, F.; Charitos, I.A.; Di Cosola, M.; Cazzolla, A.P. Focus on the cariogenic process: Microbial and biochemical interactions with teeth and oral environment. J. Biol. Regul. Homeost. Agents 2021, 35, 2. [CrossRef]

8. Claydon, N. Current concepts in toothbrushing and interdental cleaning. Periodontology 2000 2008, 48, 10-22. [CrossRef] [PubMed]

9. Heikkinen, A.M.; Raisanen, I.T.; Tervahartiala, T.; Sorsa, T. Cross-sectional analysis of risk factors for subclinicalperiodontitis; active matrix metalloproteinase- 8 as a potentialindicator in initial periodontitis in adolescents. J. Periodontol. 2019, 90, 484-492. [CrossRef] [PubMed]

10. Cifcibasi, E.; Koyuncuoglu, C.Z.; Baser, U.; Bozacioglu, B.; Kasali, K.; Cintan, S. Comparison of manual toothbrushes with different bristle designs in terms of cleaning efficacy and potential role on gingival recession. Eur. J. Dent. 2014, 08, 395-401. [CrossRef] [PubMed]

11. Cirulli, N.; Cantore, S.; Ballini, A.; Perillo, L.; Giannico, O.V.; Tafuri, S.; De Vito, D.; De Vito, D. Prevalence of caries and dental malocclusions in the apulian paediatric population: An epidemiological study. Eur. J. Paediatr. Dent. 2019, 20, 100-104. [CrossRef] [PubMed]

12. Watts, A.; Kurokawa, N.; Hillmyer, M.A. Strong, Resilient, and Sustainable Aliphatic Polyester Thermoplastic Elastomers. Biomacromolecules 2017, 18, 1845-1854. [CrossRef] [PubMed]

13. Claydon, N.; Addy, M.; Scratcher, C.; Ley, F.; Newcombe, R. Comparative professional plaque removal study using 8 branded toothbrushes. J. Clin. Periodontol. 2002, 29, 310-316. [CrossRef] [PubMed]

14. Ballini, A.; Cantore, S.; Signorini, L.; Saini, R.; Scacco, S.; Gnoni, A.; Inchingolo, A.D.; De Vito, D.; Santacroce, L.; Inchingolo, F.; et al. Efficacy of Sea Salt-Based Mouthwash and Xylitol in Improving Oral Hygiene among Adolescent Population: A Pilot Study. Int. J. Environ. Res. Public Health 2020, 18, 44. [CrossRef] 
15. Löe, H.; Theilade, E.; Jensen, S.B. Experimental Gingivitis in Man. J. Periodontol. 1965, 36, 177-187. [CrossRef]

16. Von Der Fehr, F.R.; Löe, H.; Theilade, E. Experimental Caries in Man. Caries Res. 1970, 4, 131-148. [CrossRef] [PubMed]

17. Greene, J.G.; Vermillion, J.R. The Simplified Oral Hygiene Index. J. Am. Dent. Assoc. 1964, 68, 7-13. [CrossRef]

18. Hennequin-Hoenderdos, N.; Van Der Sluijs, E.; Van Der Weijden, G.; Slot, D.; Hennequin-Hoenderdos, N. Efficacy of a rubber bristles interdental cleaner compared to an interdental brush on dental plaque, gingival bleeding and gingival abrasion: $\mathrm{A}$ randomized clinical trial. Int. J. Dent. Hyg. 2017, 16, 380-388. [CrossRef]

19. Wainwright, J.; Sheiham, A. An analysis of methods of toothbrushing recommended by dental associations, toothpaste and toothbrush companies and in dental texts. Br. Dent. J. 2014, 217, E5. [CrossRef]

20. Ballini, A.; Tetè, S.; Scattarella, A.; Cantore, S.; Mastrangelo, F.; Papa, F.; Nardi, G.M.; Perillo, L.; Crincoli, V.; Gherlone, E.; et al. The role of anti-cyclic citrullinated peptide antibody in periodontal disease. Int. J. Immunopathol. Pharmacol. 2010, $23,677-681$. [CrossRef]

21. Inchingolo, F.; Tatullo, M.; Abenavoli, F.M.; Marrelli, M.; Inchingolo, A.D.; Inchingolo, A.M.; Dipalma, G. Non-Hodgkin lymphoma affecting the tongue: Unusual intra-oral location. Head Neck Oncol. 2011, 3, 1. [CrossRef] [PubMed]

22. Inchingolo, F.; Tatullo, M.; Marrelli, M.; Inchingolo, A.M.; Inchingolo, A.D.; DiPalma, G.; Flace, P.; Girolamo, F.; Tarullo, A.; Laino, L.; et al. Regenerative surgery performed with platelet-rich plasma used in sinus lift elevation before dental implant surgery: An useful aid in healing and regeneration of bone tissue. Eur. Rev. Med. Pharmacol. Sci. 2012, 16, 1222-1226.

23. Davide, A.; Raffaella, A.; Marco, T.; Michele, S.; Syed, J.; Massimo, M.; Marco, F.; Antonio, A. Direct restoration modalities of fractured central maxillary incisors: A multi-levels validated finite elements analysis with in vivo strain measurements. Dent. Mater. 2015, 31, e289-e305. [CrossRef] [PubMed]

24. Ballini, A.; Scattarella, A.; Crincoli, V.; Carlaio, R.G.; Papa, F.; Perillo, L.; Romanazzo, T.; Bux, M.V.; Nardi, G.M.; Dituri, A.; et al. Surgical treatment of gingival overgrowth with 10 years of follow-up. Head Face Med. 2010, 6, 19. [CrossRef] [PubMed]

25. Ciavarella, M.; Guiglia, R.; Campisi, G.; Di Cosola, M.; Di Liberto, C.; Sabatucci, A.; Escudero, N.; Bascones, A.; Muzio, L.L. Update on gingival overgrowth by cyclosporine A in renal transplants. Med. Oral Patol. Oral Cir. Bucal. 2007, $12,19-25$.

26. Ballini, A.; Capodiferro, S.; Toia, M.; Cantore, S.; Favia, G.; De Frenza, G.; Grassi, F. Evidence-Based Dentistry: What's New? Int. J. Med. Sci. 2007, 4, 174-178. [CrossRef]

27. Zimmer, S.; Ozturk, M.; Barthel, C.R.; Bizhang, M.; Jordan, R.A. Cleaning Efficacy and Soft Tissue Trauma after Use of Manual Toothbrushes with Different Bristle Stiffness. J. Periodontol. 2011, 82, 267-271. [CrossRef]

28. Otsuka, R.; Nomura, Y.; Okada, A.; Uematsu, H.; Nakano, M.; Hikiji, K.; Hanada, N.; Momoi, Y. Properties of manual tooth-brush that influence on plaque removal of interproximal surface in vitro. J. Dent. Sci. 2020, 15, 14-21. [CrossRef]

29. Hoogteijling, F.; Hennequin-Hoenderdos, N.; Van Der Weijden, G.; Slot, D.; Hennequin-Hoenderdos, N. The effect of tapered toothbrush filaments compared to end-rounded filaments on dental plaque, gingivitis and gingival abrasion: A systematic review and meta-analysis. Int. J. Dent. Hyg. 2017, 16, 3-12. [CrossRef] [PubMed] 